Sharif University of Technology
Scientia Iranica
SCIENTIA
I RAN I CA

\title{
Analyses of seismicity parameters of the August 11th, 2012, Ahar-Varzaghan earthquakes in north-western Iran
}

\author{
S. Ommi and H. Zafarani*
}

International Institute of Earthquake Engineering and Seismology (IIEES), Tehran, Iran.

Received 18 August 2014; received in revised form 6 May 2015; accepted 22 June 2015

\section{KEYWORDS}

Seismicity patterns;

$b$-value;

$Z$-value;

Ahar-Varzaghan

earthquake;

Earthquake

precursors.

\begin{abstract}
North-western Iran (Azerbaijan province), one of the most seismic regions of the country, has experienced many seismic events during its long history. The recent dual earthquake with $M_{w}=6.4$ and $M_{w}=6.3$ struck the Ahar-Varzaghan area in Azerbaijan province in 2012.8.11 and caused a lot of fatalities. In this paper, the varieties of several seismic parameters, such as the $b$-value of the Gutenberg-Richter relation and standard deviation, $Z$, have been investigated to explore the temporal and spatial changes of seismicity patterns. Calculating and comparing these data before and after the occurrence of earthquake demonstrate some information about anomaly preceding main shocks. Temporal variations of $b$-value show a clear decrease before the 2012 AharVarzaghan dual earthquakes. Considering the spatial changes in the $b$-values, it is possible to recognize a zone with abnormal low $b$-values around the epicenter of these events. The variation of the $b$ and $Z$-values around the epicenter shows preparedness of the region before the occurrence of the main shock of Ahar-Varzaghan earthquake.
\end{abstract}

(C) 2016 Sharif University of Technology. All rights reserved.

\section{Introduction}

Statistical seismology deals with the analysis of spatial and temporal seismicity patterns. It provides a useful tool for better understanding of different geodynamics and seismotectonic processes within a seismogenic zone. Statistical seismology is used to obtain new and important insights into earthquake cycles and improve seismic hazard research [1-3]. There are numerous activities for studying temporal and spatial variations of seismicity patterns which are considered as the precursors in large earthquakes [4-7] among which there are some examples that show the seismic quiescence trends before some large events.

\footnotetext{
*. Corresponding author. Tel.: +982122803647; Fax: +982122833865

E-mail addresses: s.ommi@iiees.ac.ir (S. Ommi)

h.zafarani@iiees.ac.ir (H. Zafarani)
}

For example, statistical analyses of seismicity changes showed that the seismic quiescence anomalies had appeared around the epicenters before the $2008 M_{s}$ 8.0 Wenchuan earthquake in China [8] and the $2011 M$ 9.0 Tohoku earthquake in Japan [9].

The well-known Gutenberg-Richter law is an empirical formula widely accepted in the statistical seismology. This formula defines the relationship between frequencies and magnitudes of the earthquakes [10], and it is shown as follows:

$$
\log N(M)=a-b M,
$$

where, $N$ is the number of earthquakes with the magnitudes greater than or equal to $M$ occurred in a given region and in a time interval of $T$; $a$ is the number of events with the magnitudes greater than $0 ; b$ is the slope of frequency-magnitude, showing the ratio of the number of small to the number of large earthquakes; and $a$ and $b$ are positive parameters indicating the level 
and character of seismicity in the region. The changes of small to large earthquakes ratio could be assessed by variations of $b$-value of Gutenberg-Richter law; the higher the value of $b$, the lower the number of occurred earthquakes at larger magnitudes; the lower the value of $b$, the higher the number of occurred earthquakes at larger magnitudes. Therefore, these parameters are effective in studying the seismic activities preceding a main shock. Assessing the variation of $a$ and $b$ value before the main shock has been suggested in some studies in order to investigate seismicity of the region [11-15].

Thus, this kind of calculation is fundamental in precursory investigations. The $b$-value is often interpreted to be linked to the factors such as material heterogeneity, seismotectonic regime, and applied shear stress. Typical $b$-values are between 0.6 and 1.4 with a global mean of one. $b$ values less than one indicate the area of crustal homogeneity and high stress and $b$ values greater than one show the crustal heterogeneity and low stress [16]. Montuori et al. [17] have studied the crustal heterogeneity in Wellington region, New Zealand, by mapping the spatial distribution of $b$-values. The statistical variations of $b$-values have been measured by laboratory tests $[18,19]$. The values have been predicted by theoretical or numerical models [20] and observed in different tectonic environments $[5,21,22]$. It has been shown that the decrease in $b$-value could be related to the increase in shear stress or effective stress levels before probable large earthquakes [5,21-24].

According to Wiemer and co-authors [23], low $b$ values may be correlated to the rupture asperity, the nucleation zone of earthquakes, and a ruptured locked part of the fault. Recently, Schorlemmer \& Wiemer [2] investigated the magnitude distribution of microseismicity before the Park field earthquake of 28 September $2004(M=6.0)$ and interpreted the unusual low $b$-value in the region as indicative of high stress on the fault. Some authors $[25,5]$ have suggested that it is possible to devise an earthquake prediction system based on the changes of $b$-values. Study of seismicity changes of the 1995 Kobe earthquake $(M=7.2)$ in Japan showed that both seismic quiescence and activation were detected before the main shock [26]. Investigation of seismicity changes has given a better understanding of seismogenic process and it has provided useful information for seismic risk estimation/prediction. Schorlemmer et al. [27] suggested a method for stationary measuring of $b$-values and found it useful in probabilistic forecasting of coming earthquakes.

As mentioned above, besides $b$-value measurements, the seismicity-rate changes, which may be associated with the physical properties of the seismogenic zone, could be useful precursors for the main future shocks. Rundle et al. [28] have discussed the longstanding question on the highest occurrence probability of large earthquake $(M>6.0)$ during the time periods of smaller event activation or smaller event quiescence. Their results led to the conclusion that California seismicity was more likely characterized by quiescence than activation.

Statistical $Z$ test, used in several studies [15,2931 , is a proper approach for studying the changes of seismicity-rate and seismic quiescence or acceleration. For example, $Z$-mapping approach measures the difference between the seismicity-rate, within moving time windows, and background rate by standard deviate $Z$. It generates an array of comparisons that cover all available times and spaces, and could be searched for all anomalous departures from the normal seismicityrate [32]. Katsumata and Kasahara [33] used the contour plot of $Z$-value to identify precursory seismic quiescence before the 1994 Kurile earthquake $\left(M_{w}=\right.$ 8.3) in Japan. Chouliaras [34] reported a spatial extent of a quiescence period before the 2008 Greece earthquake $(M=6.4)$ using $Z$-mapping approach.

On August 11th, 2012, an earthquake with $M_{w}=$ 6.4 occurred near Ahar-Varzaghan in the east of Azerbaijan, NW of Iran, about $60 \mathrm{~km}$ to the northeast of Tabriz. The first shock was followed by another large event $\left(M_{w}=6.3\right)$ about 11 minutes later. The mentioned dual shock caused about 327 causalities, severely destroying more than 20 villages and damaging many buildings in Ahar and Varzaghan towns; it located around $20 \mathrm{~km}$ from the epicentral area. The most precise location has been estimated by the Institute of Geophysics of Tehran University (IGTU), based on its permanent seismic stations, in the NW Iran (i.e., Tabriz Seismic Network). Relocating the main shocks showed that both events had occurred approximately at the same coordinates $\left(38.43^{\circ} \mathrm{N}, 46.73^{\circ} \mathrm{E}\right)$, nearly $15 \mathrm{~km}$ to the southeast of Varzeghan and about $25 \mathrm{~km}$ to the southwest of Ahar. The focal depths of the first and second shocks were 9 and $16 \mathrm{~km}$, respectively. According to Razzaghi et al. [35], based on the CMT solution, the focal mechanisms for both events correspond to the right-lateral strikeslip faulting on E-W trends parallel to the aftershock sequence and South Ahar fault. However, the second main shock $\left(M_{w}=6.3\right)$ also shows a notable reverse component.

\section{Data and method}

On August 11th, 2012, two earthquakes with $M_{w}=6.4$ and $M_{w}=6.3$ occurred near Ahar-Varzaghan area in the northwest of Iran (Figures 1 and 2). This seismic event was one of the largest and most destructive events happened at least in the last decade in this region. This research focuses on the variations of the $b$-value and seismicity-rate regarding the mentioned earthquakes. These events occurred on a fault in the northeast edge 


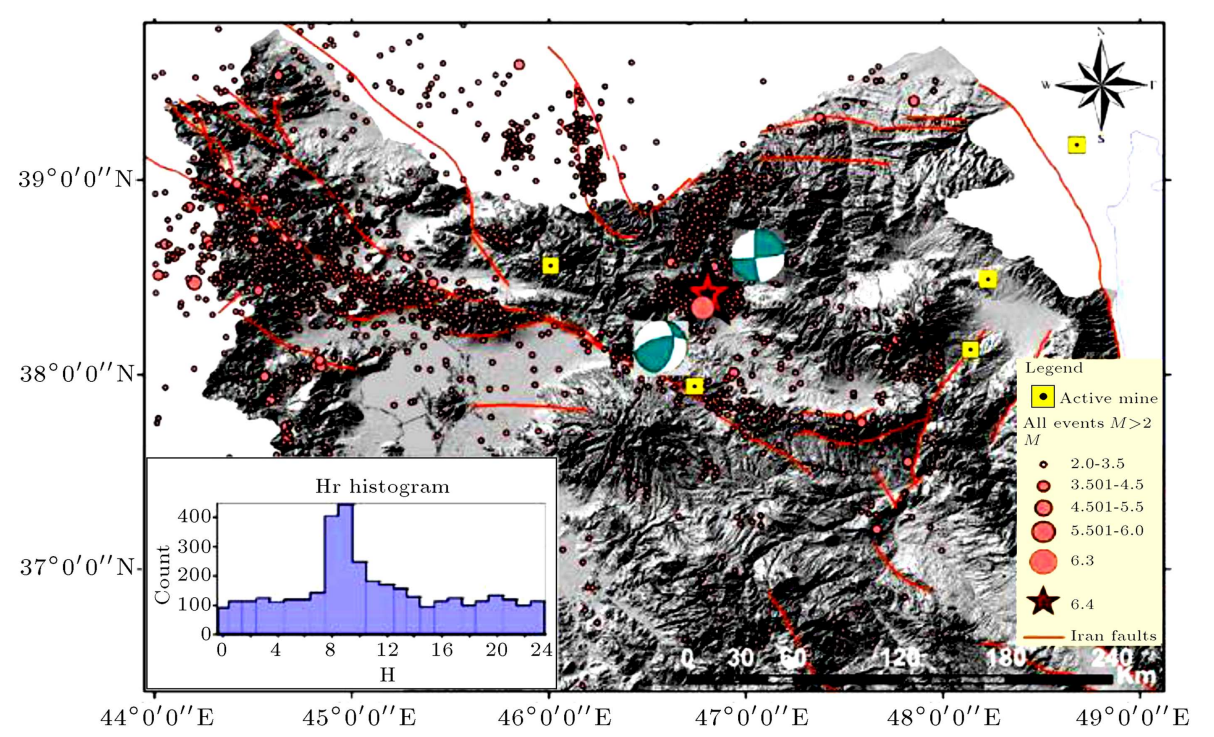

Figure 1. Map of NW Iran: major faults and distribution of the epicenters of earthquakes with the magnitude greater than 2 in 2008.01.01 to 2012.10.20 extracted from the IIEES and IGUT catalogs. Red lines: major faults; yellow squares: some active mines in the region. Histogram of events during day and night is shown in this figure.

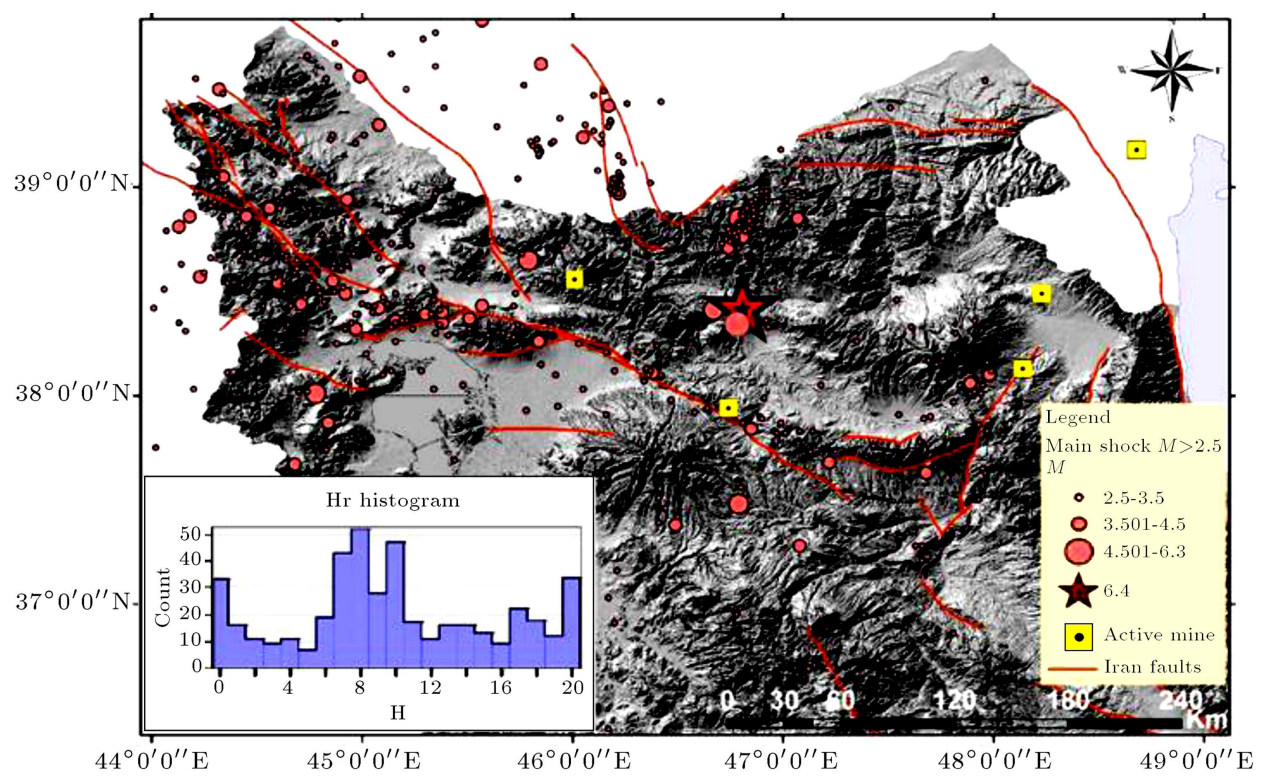

Figure 2. The location of main events with the magnitudes $M_{N} \geq M_{C}$, reported by IIEES and IGUT in 2008.01 .01 to 2012.10.20, and focal mechanism of dual earthquakes of Ahar-Varzaghan (2012). (The information about the focal mechanisms of these two events has been derived from CMT.) Red line: major faults; yellow squares: active mines. Histogram of events during day and night is shown in this figure. The events caused by artificial explosions and aftershocks have been removed.

of the Tabriz fault, one of the most seismically active faults in Iran [36].

Provision of the earthquake catalog is the first step in studying the seismic properties of certain areas. Gathering the complete and appropriate seismic data is a crucial part of this study, which has a noticeable effect on future studies. However, sometimes, seismic data in a specific time period could be detected as incomplete or manmade events, and must be corrected exactly. The proper data must be gathered and processed to provide a homogenous catalog. Determination of the seismic parameter $b$ before and after earthquake contains effective information about stress level variability in the region. Therefore, its temporal and spatial variability has been investigated in this research. In this regard, the correlation between temporal and spatial reductions of $b$-values is primarily investigated, using a homogenous earthquake catalog. Another approach in studying seismicity is to determine the seismicity-rates using $Z$-value. Here, the $Z$-value has been estimated 
to illustrate the obvious anomalous seismicity-rate and seismic quiescence that offers valuable information.

The artificial earthquakes (i.e., man-made) should be removed from the catalog prior to any further investigation. Most quarry activities inside the network are made by the Azerbaijan cement production plant, located in the north of the earthquake location. The mining explosions are carried out from local time 8:00 to 11:00 Am. Therefore, it is easy to identify the areas with highly active quarries by calculating the day-tonight ratio of the number of events. Figure 1 shows the area with all events. Dense clusters of events are seen in the north and northeast of Tabriz.

The effect of events caused by mine explosions are identified in the regional catalog by plotting the distribution histogram of all events in day and night. The locations of such artificial events surrounding the active mines are distinguished in Figure 1. These events have been removed from the catalog considering both mine location and completeness magnitude $\left(M_{c}=\right.$ 2.4; see below discussion).

The histogram returned to its normal shape by replotting the distribution curve of the events per hour. Figure 2 shows distribution of the main events after removing the artificial events.

The data has been provided by the Institute of Geophysics, University of Tehran (IGUT), and the International Institute of Earthquake Engineering and Seismology (IIEES). It has been used for developing a correct homogenous earthquake catalog. The duplicate events have been removed, concerning the events recorded in more than one catalog. All magnitude scales $\left(M_{N}\right.$ and $M_{L}$ for IGUT and IIEES catalogs, respectively) have been converted to the moment magnitude, $M_{w}$. The earthquake catalog of the study area covers the records of 3248 events in the latitudes $36-40 \mathrm{~N}^{\circ}$ and longitudes $44-48 \mathrm{E}^{\circ}$ from 01.01.2008 to 20.10.2012. The earthquakes have depths and magnitudes of from 1 to $\sim 36 \mathrm{~km}$ and $2-6.4 M_{N}$, respectively. The threshold or completeness magnitude $\left(M_{c}\right)$, defined as a minimum detectable magnitude [37], fluctuates based on the seismic networks and data processing methods [38]. Precise estimation of $M_{c}$ is important in all seismicity based studies as a maximum number of available events should be considered in order to achieve highly qualified results. Maximum curvature method has been applied along with a moving window method for estimating the magnitude of completeness, $M_{c}$, and investigating its temporary changes. The moving window method has a set of maximum 100 events for computing the parameters shifting forward by 25 events for the entire sequence. Spatial distribution of $M_{c}$ is obtained by the grading method of Wiemer and Wyss [32] (Figure 3). Spatial and temporal variations of $M_{c}$ show no significant changes for this parameter. Uniform variation of

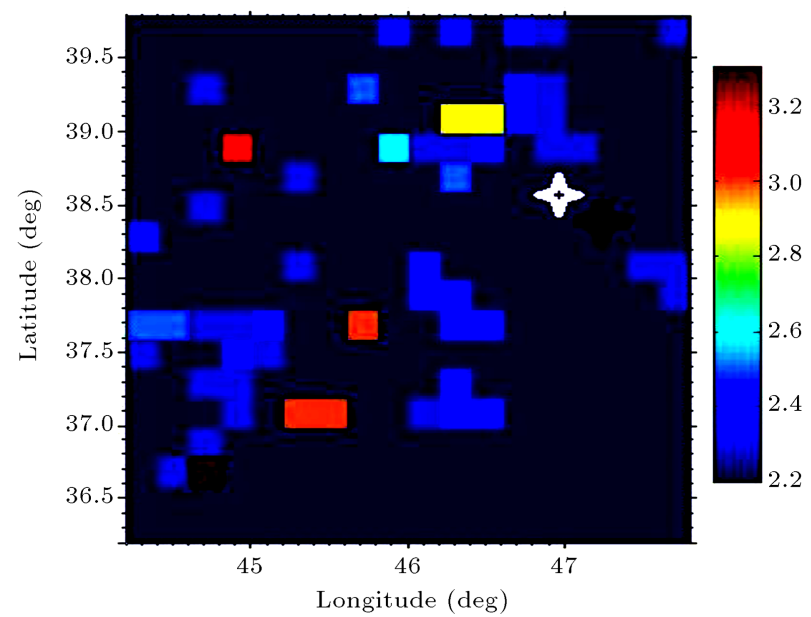

(a)

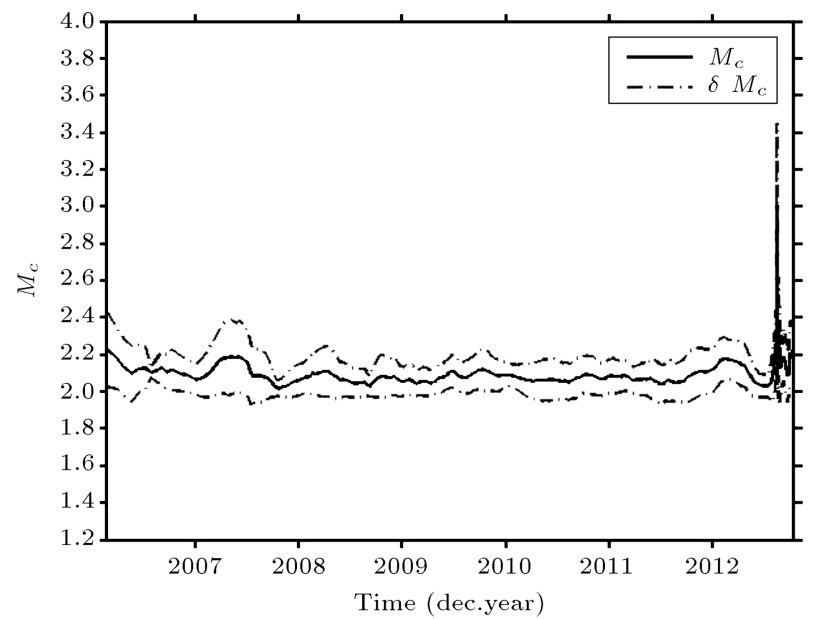

(b)

Figure 3. Spatial (a) and temporal (b) variations of magnitude of completeness $\left(M_{c}\right)$ in 2006.01 .03 to 2012.10.20. White star: the location of main shock $\left(M_{w}=6.4\right)$; black star: the location of event with $M_{w}=6.3$.

cumulative number of earthquakes (with $M>2.4$ ) in Figure 4 confirms that decrease or increase in the number stations of network did not occur during this period of time. It should be noted that the increase in the number of data after main shock was due to aftershock occurrences. According to the obtained results, all events with the magnitudes larger than $M_{c}=2.4$ have been reported homogeneously in 2006.01.03-2012.10.20 $M_{c}$ and vary between 2 and 2.4; therefore, $M_{c}=2.4$ has been selected as the threshold of magnitude for the region. Finally, 1472 earthquakes with magnitudes larger than $M_{c}=2.4$ have been selected in the area between $44.0-48.0^{\circ} \mathrm{E}$ and $36.0-40.0^{\circ} \mathrm{N}$ to study the temporal variations of $b$-value (Figure 5). It is important that de-clustering was not performed to detect temporal variations of seismic $b$ value as in Wu et al. [15]. According to the temporal changes of the $b$-value, variation of seismicity could be 


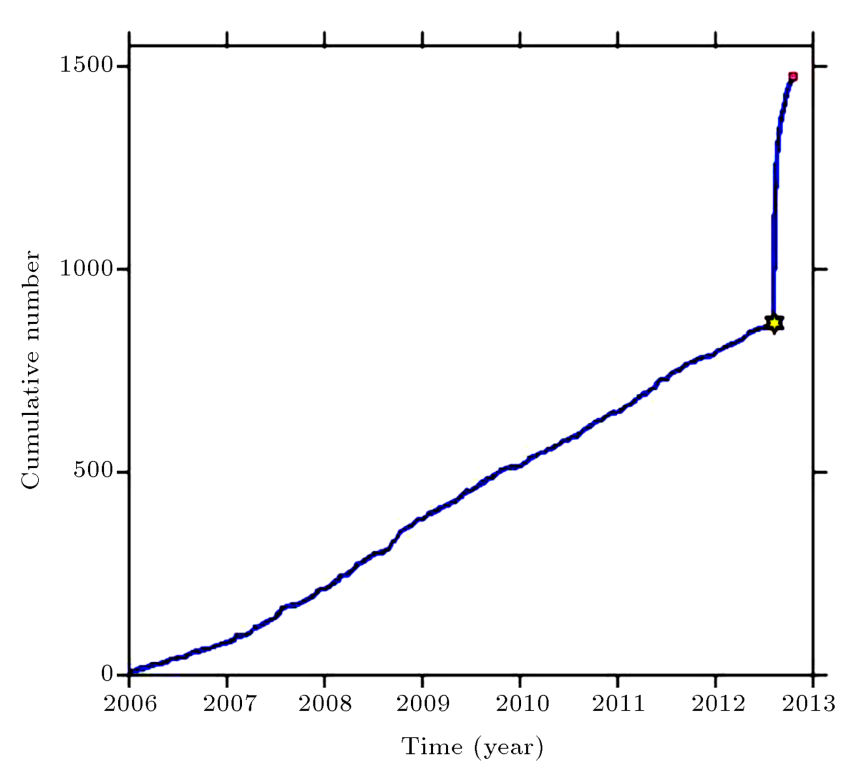

Figure 4. Cumulative number of earthquakes in 2006.01.03 to 2012.10.20. Yellow star: Occurrence time of dual earthquake $\left(M_{w}=6.3\right.$ and $\left.M_{w}=6.4\right)$.

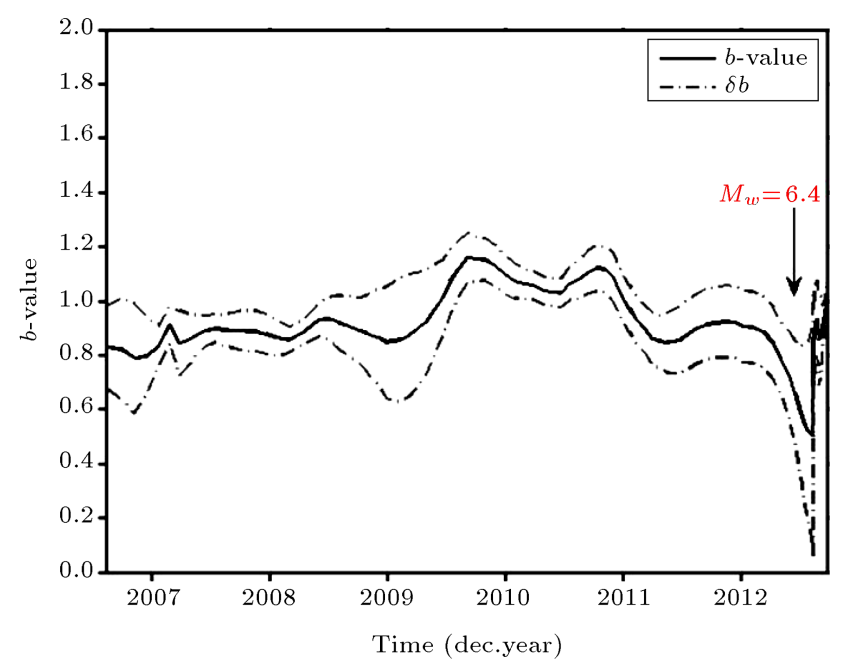

Figure 5. Temporal variations of $b$-value for earthquakes with $M_{w} \geq 2.4$ from 2006.01.03 to 2012.10.20 within the study area. Dash lines: the events with $M_{w} \geq 6$.

divided in two periods of time 2009.01.01-2011.01.01 (as period A) and 2011.01.02-2012.08.10 (as period B). However, the data between 2008.01.03 and 2012.10.20 has been selected to get the special variations of $b$ values before the 2012 Ahar-Varzaghan earthquake. For this purpose, de-clustering the events must be done as an initial step for future activities.

There are several methods of aftershock identification, such as hand procedure, windowing method, and cluster method [4]. Using the $Z$ map software, Gardner \& Knopoff [39], Burkhard \& Grönthal [40], and Reasenberg [41] methods were applied for comparing different de-clustering schemes and removed aftershocks were detected $71 \%, 75 \%$, and $46 \%$, respectively. Since the parameters of Reasenberg [41] method have not been modified/adopted for the seismicity regime of Iran, applying this method for Iran could not be justified. Preferably, Gardner \& Knopoff's [39] method with slightly more remained main shocks was selected as a final choice for de-clustering the catalog.

Accordingly, the aftershocks have been removed from the catalog by Gardner \& Knopoff's [39] algorithm, remaining 445 events. ZMAP software [42] has been applied for all computations. However, $Z$-value is calculated for statistic testing and comparing the seismicity rates.

This process has resulted in $32 \%$ reduction in the total number of events. Then, the variation of $b$-values has been calculated versus time and location. This calculation has been carried out by maximum likelihood method, presented by Aki [43], in the following formula:

$$
b=\log e /\left(M_{\text {mean }}-M_{\text {min }}\right),
$$

where, $M_{\text {mean }}$ is mean magnitude and $M_{\text {min }}$ is minimum magnitude of the sample. The latter is computed as follows:

$$
M_{\min }=M_{c}-\Delta M / 2
$$

where, $\Delta M$ is the magnitude bin, here considered as $\Delta M=0.1$ [27]. The temporal variation of $b$-value is plotted in Figure 5.

An automatic bootstrapping method has been used to smooth the plot. In this research, different numbers of events have been tested in the sliding windows (40, 50, 60, 70, 80, and 100). Accordingly, different overlap/shift lengths have also been studied to obtain the best resolution. Finally, a sliding/shifting time window of 50 events has been selected based on the best time resolution result. The gridding method of Wiemer and Wyss [32] has been applied in order to visualize the spatial distribution of $b$-values in the study area. Therefore, the earthquakes are projected onto a plane, and the study area is gridded on a net of 0.2 degree in both the latitude and longitude directions. $b$-value has been estimated for circular epicentral areas centered at each gird point using 50 nearest earthquakes. The search radius can have an ascending trend in case of existing insufficient events. For generating spatial changes in $b$-value (Figure 6), data was selected from 2008.1.1 to 2012.7.28 and aftershocks were manually removed from the catalog. Other de-clustering methods were used and the same result was achieved. In applied de-clustering methods, the reduction of the $b$-value around the location of epicenter was observed with different values of $b$.

Conducting Utsu test [44] is also effective in studying the similarities between two samples selected from statistical population. The variation probability of magnitude frequency distribution could be 


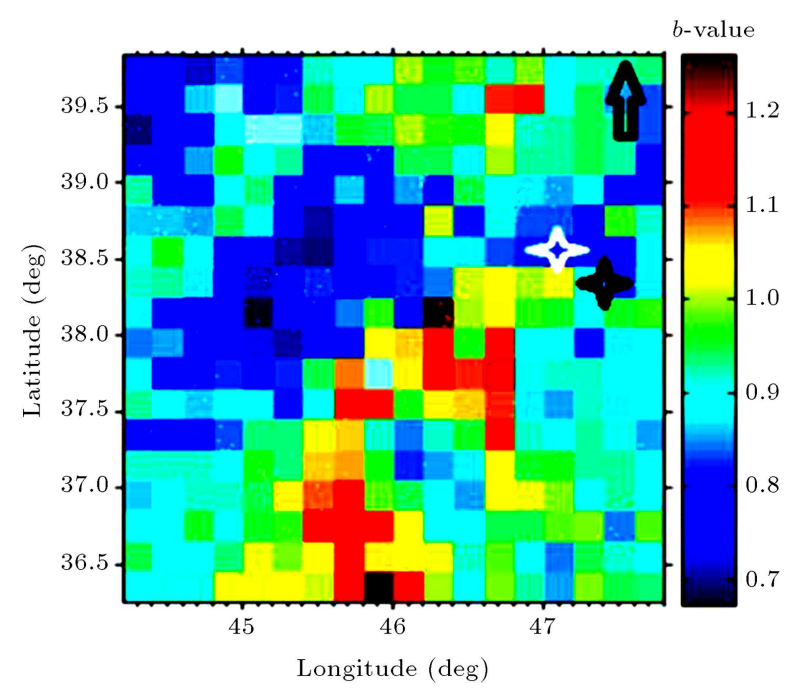

Figure 6. Variations of $b$-value versus location before the 2012 dual earthquakes of Ahar-Varzaghan. White star: location of the main shock $\left(M_{w}=6.4\right)$; black star: location of the event with $M_{w}=6.3$; and colored band: the variation of $b$-values $(0.7-1.2)$.

assessed by calculating $P$-value through the following formula [44]:

$$
P=\exp \left(-\left(\frac{d A}{2}\right)\right)-2,
$$

where:

$$
\begin{aligned}
d A= & -2 N \ln (N)+2 N_{1} \ln \left(N_{1}+N_{2} b_{1} / b_{2}\right) \\
& +2 N_{2} \ln \left(N_{2}+N_{1} b_{2} / b_{1}\right)-2,
\end{aligned}
$$

and:

$$
N=N_{1}-N_{2} \cdot N_{1}
$$

$N_{1}$ and $N_{2}$ are total events for calculating the $b$-values of $b_{1}$ and $b_{2}$, respectively. At the end, we selected two periods of time (period A $\left(b_{1}=1.06 ; N_{1}=137\right)$ and period $\left.\mathrm{B}\left(b_{2}=0.8 ; N_{2}=112\right)\right)$, that are identical in duration, and measured their frequency-magnitude distributions (Figure 7).

In order to segregate and indicate anomalies from back ground, different statistical procedures were developed. In this part, segregating different seismic boundaries was done according to the statistical view of earthquake occurrences.

Seismic variations could be measured according to seismic rate changes in different temporal windows. Considering the above explanation, variable $Z$ can be used for investigating seismic rates. The null hypothesis is to start with the assumption that two samples have similar mean seismic rates and significant differences would be rejected. Based on this theory, a new method for measuring seismic variations was developed by Haberman [45].

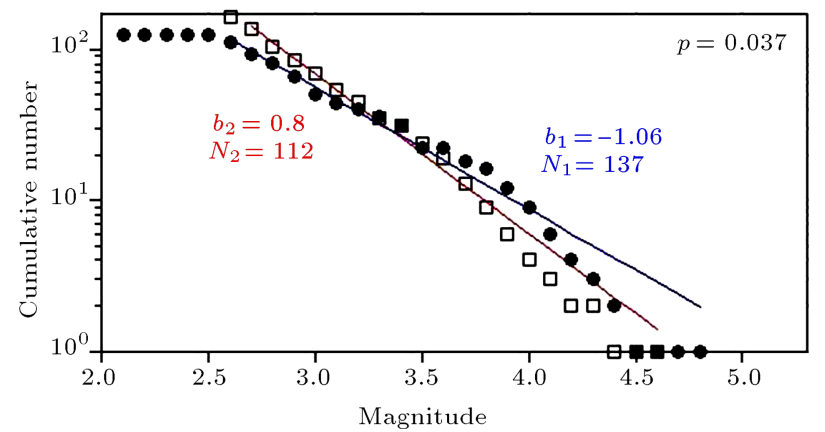

Figure 7. Comparing the frequency distributions of magnitudes in 2009.1.1 to 2011.1.1 $(b=1.06)$ and 2011.1.2 to $2012.8 .10(b=0.8)$. Conducting $P$-test shows the similarities between their distributions.

In this research, $Z$ test has also been carried out in order to study the variation of seismicity-rate caused by the Ahar-Varzaghan earthquake. $Z$-value is computed as follows:

$$
Z=\frac{R_{1}-R_{2}}{\sqrt{\frac{S_{1}}{N_{1}}}+\sqrt{\frac{S_{2}}{N_{2}}}} Z,
$$

where, $R_{1}$ and $R_{2}$ are mean activity rates during the two periods; $S_{1}$ and $S_{2}$ are the standard deviations of the rates; $N_{1}$ and $N_{2}$ are numbers of earthquakes in each time period [45]. Positive and negative values of $Z$ indicate the decrease and increase in seismicity, respectively [29].

In the first step, the rate of selected samples was determined to be compared with background rate. Then, the cumulative number of earthquakes has been plotted as a function of time, in each circle with different radius $(40,50,70$, and $90 \mathrm{~km})$ centered at the epicenter of the Ahar-Varzaghan earthquake at $38.43^{\circ} \mathrm{N}$, and $46.73^{\circ} \mathrm{E}$. The standard deviation $(Z)$ has been measured for generating $A S(t)$ function [32]. To calculate $A S(t)$ function, the de-clustered catalog has been updated up to 2013.4.18. This function represents the standard deviate $Z$, comparing the rates in the two parts of the period before and after the point of division, which move from $\left(t_{0}+t_{w}\right)$ to $\left(t_{e}-t_{w}\right) ; t_{0}$ is the beginning, $t_{e}$ the end, and $t_{w}$ the window length $[45,46]$. Various window lengths were tested and the one with the best resolution/detection of rate changes was selected. Eventually, $R=50 \mathrm{~km}$, bin length of 28 days, and window size of $W l=0.7$ year have been selected as the most stable and rigorous parameters of each circle, centered around the epicenter (Figure 8). According to the rate variation in Figure 8 , the selected periods (i.e. periods $\mathrm{A}$ and $\mathrm{B}$ ) for measuring anomaly changes in seismicity could be the best choices. In the next step, $Z$-value has been plotted based on the results of the cumulative number of earthquakes. Seismicity-rate variations have been compared between the periods $\mathrm{A}$ and $\mathrm{B}$, one day before the Ahar-Varzaghan main shock. 


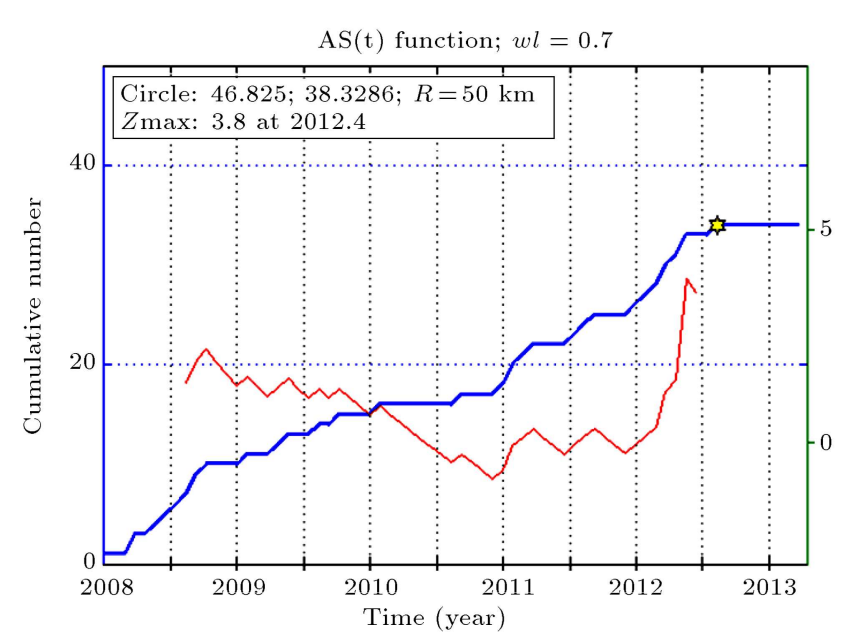

Figure 8. The cumulative distributions of events (blue color) versus time in $50 \mathrm{~km}$ from the epicenter of the 2012 Ahar-Varzaghan main shock. Yellow star: time of the main shock; red color: $Z$-value showing a clear decrease corresponding to the time of the main shock.

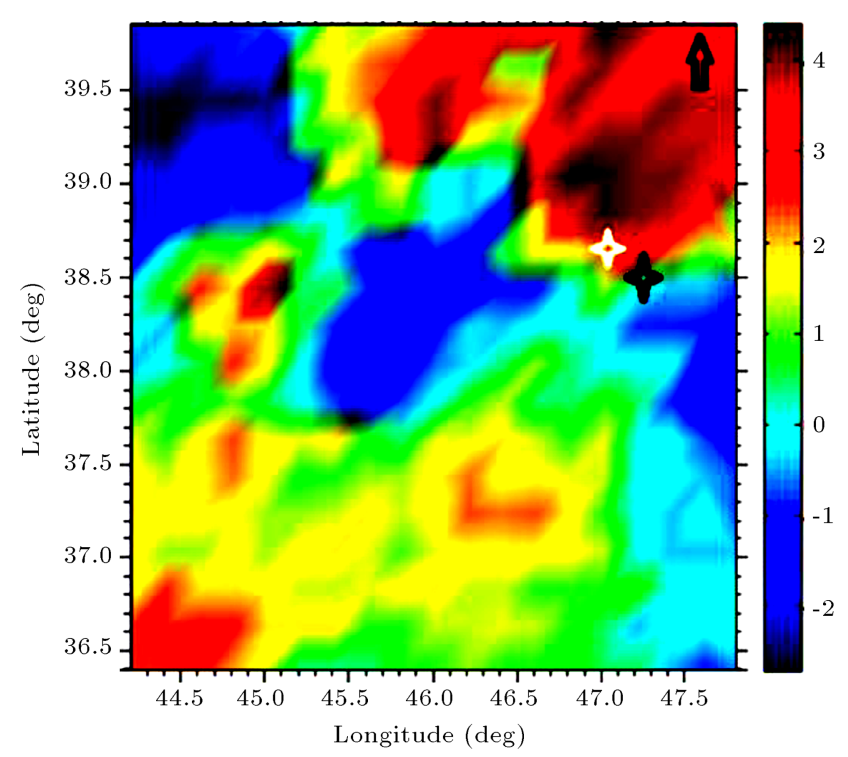

Figure 9. Map of the variation of $Z$-value versus location. $Z$-value compares the seismic rates of two periods of $\mathrm{A}$ and $\mathrm{B}$. Red color: positive values of $Z$, showing seismicity decrease; blue color: negative value of $Z$, showing seismicity increase; white star: location of the main shock $\left(M_{w}=6.4\right)$; and black star: location of the event with $M_{w}=6.3$.

$Z$-value has been measured using gridding technique, at each grid point, spaced at $0.2^{\circ}$ including the 50 nearest events [32] (see Figure 9).

\section{Results and discussion}

Temporal and spatial plots of $b$ - and $Z$-values of the earthquake have provided useful information about precursory signals of the 2012 Ahar-Varzaghan event. The resulted temporal variation for the $b$-value graph clearly exhibits dramatic drops during the second half of 2012 (Figure 5). These remarkable drops can be correlated with the strong shock in 2012.08.11 $\left(M_{w}=\right.$ $6.4)$.

Studying variations of the $b$-value versus location can be a criterion for seismicity level. The old hypothesis of reduction in the $b$-value before events has been presented by Smith [47] and Fielder [48].

Scholz [18] studied the variations of $b$-value and showed the relevance of this parameter and stress level. Dramatic decrease in the $b$-value before major earthquakes might be correlated to increase in the certain stress level $[5,22,49]$.

Figure 5 shows an obvious increase in the $b$-value in May 2012 to August 2012. It is followed by a notable decrease reaching $0.6-0.7$ a couple of months preceding the 2012 Ahar-Varzaghan earthquake. Such temporal variation of $b$-value was similarly seen before occurrence of Sumatra earthquake [21]. Temporal variations of $b$-value were shown in Figure 5. Its spatial variations have also been estimated for 2008.01.01 to 2012.07 .28 , 13 days before the Ahar-Varzaghan earthquake $\left(M_{w}=6.4\right)$, and presented in Figure 6 . In the figure, blue and red colors denote low and high $b$-values, respectively.

High spatial changes in $b$-value show the significant spatial variability (Figure 6). The spatial low $b$ value in a region might determine where earthquake will most likely take place $[13,24,50]$. Low $b$-values (0.6-0.7) anomaly is clearly found in the vicinity of epicenter of the Ahar-Varzaghan earthquake (Figure 6) extending in the longitudes of $46.4^{\circ} \mathrm{E}$ to $47.4^{\circ} \mathrm{E}$ over an area about $5,000 \mathrm{~km}^{2}$. Final result derived from the similar investigation in Park field and St Andrea's fault showed the consistency of $b$-value reduction and earthquake occurrence [51].

The zones with low $b$-value before the AharVarzaghan earthquake can be interpreted as the potentially locked or high stress accumulated zones. They would not participate in the creeping and therefore, may be considered as capable zones for future earthquakes $[52,6]$.

In this study, two time periods have been selected before earthquake for conducting Utsu test (Eq. (3)), and their frequency magnitude distributions have been computed (Figure 7 ). The calculated $b$-values for periods A and B were 1.06 and 0.8, respectively. The two distributions are hardly probable to originate in the same mother population due to the obtained very small $p$ value $(p=0.037)$, computed by Utsu test. Besides $b$-value, the variations of seismicityrate and seismic quiescence have been measured as well. No earthquake has occurred in about 0.7 year preceding the main shock of the Ahar-Varzaghan dual earthquakes, locating in $38.43^{\circ} \mathrm{N}$ and $46.73^{\circ} \mathrm{E}$. This fact is shown in Figure 8, plotted for the cumulative number 
(upper curve) of selected earthquakes, with $R=50 \mathrm{~km}$ from the epicenter of the main shock.

The source volume of the 2012 Ahar-Varzaghan earthquakes might be included in the outstanding quiescence anomaly region. $Z$ parameter meets its peak value when the seismicity-rate begins to decrease considerably (Figure 8). The rate changes have clearly been seen, in this figure, staring from 2008.05 up to the occurrence of the main shock, then showing a slump $(Z=-0.6)$ corresponding to the main shock time.

Variations of seismicity-rate have been evaluated by standard deviation $(Z)$ and shown in Figure 9 . Two time periods, $\mathrm{A}$ and $\mathrm{B}$, are compared in this figure. The latter has been selected based on the results derived from cumulative number of events, concerning the occurrence of no earthquake in about 1 year before the main shock (Figure 8). Therefore, the seismicityrate of 1 year before the main shock has been compared to the background seismicity-rate in the study area. According to Figure 9, the epicenter of the earthquake has located in a distinct seismic quiescence region. This region is approximately correlated with the low anomaly of $Z$-value before the Ahar-Varzaghan earthquakes occurrence around the epicenter area, shown in Figure 6. Based on the similarity between geographical distributions of these two anomalies (Figures 6 and 9), the detected anomalies could be inferred to achieve reliable results. Calculation of $Z$-value distribution has been repeated with two other de-clustering methods $[40,41]$ and similar results have been obtained.

In this research, $Z$-values have been measured using seismicity-rates of two periods, 2009.01.012011.08.10 and 2011.08.10-2012.8.10 (Figure 9) in order to study the variations of seismicity-rate before and after the main shock of the 2012 Ahar-Varzaghan earthquake. The epicenter of this event (white star) has located in the negative $Z$ value, showing the ascending trend of seismicity-rate in 1 year before the main shock compared to 3.5 years.

According to Figure 9, the value of $Z$ is equal to 3.8 in the earthquake location. Therefore, concerning the $|Z|>Z_{1-\frac{\alpha}{2}}$, the null hypothesis is rejected.

\section{Conclusions}

In this research, $b$-value of Gutenberg-Richter relation, seismic quiescence, and seismicity-rates have been investigated for the 2012 Ahar-Varzaghan earthquakes, occurred in the northwest of Iran. The main results are summarized as follows:

1. Determination of magnitude of completeness $\left(M_{c}\right)$ will affect the computation of some seismic parameters such as $a$ and $b$. Therefore, it should be estimated properly in any time period. The estimation accuracy will be lowered due to the existence of non-physical data in catalog. Such data corresponds to the man-made explosions or incorrect recording, which must be identified and removed from seismic catalog. For this purpose, magnitude of completeness was estimated and the events with lower magnitudes were removed from the catalog and the variations of $b$-values were computed versus time. The minimum of $b$-value has been observed for the Ahar-Varzaghan earthquakes. Thus, reduction in the number of small events has led to a large event;

2. Calculating the $b$-value after de-clustering and mapping its distributions versus location in January 2008 to April 2012 confirms its severe reduction around the earthquake epicenter. Therefore, the Gutenberg-Richter method is suggested as the most effective model for expressing the changes in statistical specifications. The rate of small earthquakes could be searched according to the variations of the $Z$-value. In this regard, its dramatic reduction has been observed during the Ahar-Varzaghan event;

3. Seismicity-rate of the region has been mapped and compared with the background seismicity by $Z$ value for one year before the main shock. The result showed an obvious seismic quiescence precursory around the epicenter of the main shock. Furthermore, the variations of seismicity-rate before and after the 2012 Ahar-Varzaghan main shock showed an increase of seismicity-rate in one year before the event compared to 3.5 years;

4. The epicenter location is correlated with the reduction of $b$-value (Figure 6 ) and the positivity of standard deviation $(Z)$ (Figure 9). This fact describes stress distribution in the geography of the region of which the exact study depends on applying tectonic information of the region;

5. Anomaly trend correlates with the major source of seismicity in Ahar-Varzaghan and, mainly, the fault mechanism with an E-W, parallel to the coastline. Results of ground motion simulation [53] also confirm that the causative fault of this earthquake has an E-W trend. Conformity of anomaly zone with the fault rupture area also supports the validity of the statistical analyses.

\section{Acknowledgment}

The thoughtful reviews by two anonymous reviewers whom we wish to thank, strongly contributed to the clarity and the readability of this article. The authors thank Stefan Wiemer for the ZMAP software. This study was supported by the International Institute of Earthquake Engineering and Seismology (IIEES), Project No. 9612: "Prediction of Aftershock Hazard in the Iranian Plateau using the Statistical Methods." 


\section{References}

1. Bernard, P., Lyon-Caen, H., Briole, P., Deschamps, A., Boudin, F., Makropoulos, K., Papadimitriou, P., Lemeille, F., Patau, G., Billiris, H., Paradissis, D., Papazissi, K., Castarède, H., Charade, O., Nercessian, A., Avallone, A., Pacchiani, F., Zahradnik, J., Sacks, S. and Linde, A. "Seismicity, deformation and seismic hazard in the western rift of Corinth: New insights from the Corinth Rift Laboratory (CRL)", Tectonophysics, 426, pp. 7-30 (2006).

2. Schorlemmer, D., Wiemer, S. and Wyss, M. "Variations in earthquake size distribution across different stress regimes", Nature, 437, pp. 539-542 (2005).

3. White, B.J.P., Smith, R.B., Husen, S., Farrell, J. and Wong, I. "Seismicity and earthquake hazard analysis of the Teton-Yellowstone region, Wyoming", J. Volcanol. Geoth. Res., 188, pp. 277-296 (2009).

4. Rundle, J.B., Tiampo, K.F., Klein, W. and Martins, J. "Self-organization in leaky threshold systems: The influence of near-mean field dynamics and its implications for earthquakes", Proceedings of National Academy of the United State of America, 99, pp. 25142521 (2002).

5. Tsukakoshi, Y. and Shimazaki, K. "Decreased $b$-value prior to the M 6.2 Northern Miyagi, Japan, earthquake of 26 July 2003", Earth Planets Space, 60, pp. 915-924 (2008).

6. Wyss, M., Pacchiani, F., Deschamps, A. and Patau, G. "Mean magnitude variations of earthquakes as a function of depth: Different crustal stress distribution depending on tectonic setting", Geophys. Res. Lett., 35, L01307, pp. 1-6 (2008).

7. Rani, V.S., Srivastava, K., Srinagesh, D. and Dimri, V.P. "Spatial and temporal variations of $b$-value and fractal analysis for the Makran region", Mar. Geodesy, 34, pp. 77-82 (2011).

8. Huang, Q.H. "Seismicity changes prior to the Ms8.0 Wenchuan earthquake in Sichuan, China", Geophys. Res. Lett., 35(23), L23308 (2008).

9. Huang, Q.H. and Ding, X. "Spatiotemporal variations of seismic quiescence prior to the 2011 M9.0 Tohoku earthquake revealed by an improved Region-TimeLength algorithm", Bull. Seismolo. Soc. Am., 102(4), pp. 1878-1883 (2012).

10. Gutenberg, B. and Richter, C.F. "Frequency of earthquakes in California", Bull. Seismolo. Soc. Am., 34, pp. 185-188 (1944).

11. Jimenez, A., Tiampo, K.F., Levin, S. and Posadas, A.M. "Testing the persistence in earthquake catalogs: The Iberian Peninsula", EPL, 73(2), pp. 171-177 (2006).

12. Smith, W.D. "The b-value as an earthquake precursor", Nature, 289, pp. 136-139 (1981).

13. Schorlemmer, D., Neri, G., Wiemer, S. and Mostaccio, A. "Stability and significance tests for $b$-value anoma- lies: Example from the Tyrrhenian sea", Geophys. Res. Lett., 30(16), pp. 1-3 (2003).

14. Murru, M., Console, R., Falcone, G., Montuori, C. and Sgroi, T. "Spatial mapping of the $b$ value at Mount Etna, Italy, using earthquake data recorded from 1999 to 2005", J. Geophys. Res.: Solid Earth B, 112(12), NO. B12303 (2007).

15. Wu, Y.M., Chen, C.C., Zhao, L. and Chang, C.H. "Seismicity characteristics before the 2003 Chengkung, Taiwan, earthquake", Tectonophysics, 457, pp. 177$182(2008)$.

16. Udias, A., Principles of Seismology, Cambridge University Press, New York (1999).

17. Montuori, C., Falcone, G., Murru, M., Thurber, C., Reyners, M. and Eberhart-Phillips, D. "Crustal heterogeneity highlighted by spatial b-value map in the Wellington region of New Zealand", Geophys. J. Int., 183(1), pp. 451-460 (2010).

18. Scholz, C.H. "The frequency-magnitude relation of micro fracturing in rock and its relation to earthquakes", Bull. Seismolo. Soc. Am., 58, pp. 399-415 (1968).

19. Amitrano, D. "Brittle-ductile transition and associated seismicity: Experimental and numerical studies and relationship with the $b$ value", J. Geophys. Res.: Solid Earth B, 108, pp. 1-8 (2003).

20. Henderson, J., Main, I., Meredith, P. and Sammonds, P. "The evolution seismicity at Parkfiled: Observation, experiment and a fracture-mechanical interpretation", J. Str. Geol., 14(8/9), pp. 905-913 (1992).

21. Nuannin, P., Kulha'nek, O. and Persson, L. "Spatial and temporal $b$-value anomalies preceding the devastating off coast of NW Sumatra earthquake of December 26, 2004", Geophysical Research Letters, 32(11), pp. 1-4 (2005).

22. Wu, Y.M. and Chiao, L.Y. "Seismic quiescence before the 1999 Chi-Chi, Taiwan Mw7.6 earthquake", Bull. Seismolo. Soc. Am., 96, pp. 321-327 (2006).

23. Wiemer, S. and Wyss, M. "Mapping the frequencymagnitude distribution in asperities: An improved technique to calculate recurrence times", J. Geophys. Res.: Solid Earth B, 102(15), pp. 115-128 (1997).

24. Wyss, M. and Stefansson, R. "Nucleation points of recent main shocks in southern Iceland mapped by b-values", Bull. Seismolo. Soc. Am., 96, pp. 599-608 (2006).

25. Lockner, D.A. and Byerlee, J.D. "Precursory AE patterns leading to rock fracture", in Vth Conf. AE/MS Geol. Str. and Mat., édité par Hardy, pp. 45-58, Trans Tech Publication, Germany, The Pennsylvania State University (1991).

26. Huang, Q.H., Sobolev, G.A. and Nagao, T. "Characteristics of the seismic quiescence and activation patterns before the $\mathrm{M}=7.2$ Kobe earthquake, January 17 , 1995", Tectonophysics, 337(1-2), pp. 99-116 (2001). 
27. Schorlemmer, D., Wiemer, S. and Wyss, M. "Earthquake statistics at Park field, stationary of $b$ values", J. Geophys. Res.: Solid Earth B, 109(12), pp. 1-17 (2004).

28. Rundle, J.B., Holliday, J.R., Yoder, M., Sachs, M.K., Donnellan, A., Turcotte, D.L., Tiampo, K.F., Klein, W. and Kellogg, L.H. "Earthquake precursors: activation or quiescence?", Geophys. J. Int., 187, pp. 225236 (2011).

29. Maeda, K. and Wiemer, S. "Significance test for seismicity-rate changes before the 1987 Chiba-toho-oki earthquake (M6.7), Japan", Ann. Geofis., 42(5), pp. 833-850 (1999).

30. Katsumata, K. "Long term seismic quiescence started 23 years before the 2011 off the Pacific coast of Tohoku earthquake (M = 9.0)", Earth Planets Space,63, pp. 709-712 (2011).

31. Sorbi, M.R., Nilfouroushan, F. and Zamani, A. "Seismicity patterns associated with the September 10th, 2008 Qeshm earthquake, South Iran", Int. J. Earth. Sci., 101(8), pp. 2215-2223 (2012).

32. Wiemer, S. and Wyss, M. "Seismic quiescence before the Landers $(\mathrm{M}=7.5)$ and big bear $(\mathrm{M}=6.5), 1992$ earthquakes", Bull. Seismolo. Soc. Am., 84(3), pp. 900-916 (1994).

33. Katsumata, K. and Kasahara, M. "Precursory seismic quiescence before the 1994 Kurile earthquake $\left(\mathrm{M}_{\mathrm{w}}=\right.$ 8.3) revealed by three independent seismic catalogs", Pure Appl. Geophys., 155, pp. 443-470 (1999).

34. Chouliaras, G. "Seismicity anomalies prior to 8 June $2008, \mathrm{M}_{\mathrm{w}}=6.4$ earthquake in western Greece", Nat. Hazards Earth Syst. Sci., 9, pp. 327-335 (2009).

35. Razzaghi, M. and Ghafory-Ashtiany, M. "The $\mathrm{M}_{\mathrm{w}}=$ 6.4 and $\mathrm{M}_{\mathrm{w}}=6.3$ Iran earthquakes of August 11, 2012", EERI Special Earthquake Report, December (2012).

36. Jackson, J. and McKenzie, D.P. "Active tectonics of Alpine-Himalayan belt between Western Turkey and Pakistan", Geophys. J. R. Astron. Soc., 77, pp. 185264 (1984).

37. Wiemer, S. and Wyss, M. "Minimum magnitude of completeness in earthquake catalogs: Examples from Alaska, the western United States, and Japan", Bull. Seismolo. Soc. Am., 90(4), pp. 859-869 (2000).

38. Wiemer, S. and Wyss, M. "Mapping spatial variability of the frequency-magnitude distribution of earthquakes", Adv. Geosci., 45, pp. 259-302 (2002).

39. Gardner, J.K. and Knopoff, L. "Is the sequence of earthquakes southern California, with aftershocks removed Possonian?", Bull. Seismolo. Soc. Am., 64, pp. 1363-1367 (1974).

40. Burkhard, M. and Grünthal, G. "Seismic source zone characterization for the seismic hazard assessment project Pegasos by the expert group 2 (Eg1b)", Swiss J. Geosci., 102, pp. 149-188 (2009).

41. Reasenberg, P. "Second-order moment of central California seismicity", 1969-1982. J. Geophys. Res.: Solid Earth B, 90, pp. 5479-5495 (1985).

42. Wiemer, S. "A program to analyze seismicity: ZMAP", Geophys. Res. Lett., 72, pp. 373-382 (2001).

43. Aki, K. "Maximum likelihood estimate of $\mathrm{b}$ in the formula $\log N=a-b M$ and its conference limits", Bulletin of Earthquake Research, 43, pp. 237-239 (1965).

44. Utsu, T. "On seismicity", in Report of the Joint Research Institute for Statistical Mathematics, Institute for Statistical Mathematics, Tokyo, 34, pp. 139-157 (1992).

45. Habermann, R.E. "Man-made changes of seismicityrate s", Bull. Seismolo. Soc. Am., 77, pp. 141-159 (1987).

46. Wyss, M., Wiemer, S. and Zuniga, R. ZMAP a Tool for Analyses of Seismicity Patterns, Typical Applications and Uses: A Cookbook, Swiss Seismological Service (2001).

47. Smith, W. "Evidence for precursory changes in the frequency-magnitude $b$ value", Geophys. J. R. Astron. Soc., 86, pp. 815-838 (1986).

48. Fielder, G. "Local $b$ value related to seismicity", $J$. Geophys. Res.: Solid Earth B, 23, pp. 277-282 (1974).

49. Urbancic, T.I., Trifu, C.I., Long, J.M. and Toung, R.P. "Space-time correlations of $b$ values with stress release", Pure Appl. Geophys., 139, pp. 449-462 (1992).

50. Westerhaus, M., Wyss, M., Yilmaz, R. and Zschau, J. "Correlating variations of $b$ values and crustal deformation during the 1990's may have pinpointed the rupture initiation of the $\mathrm{M}_{\mathrm{w}}=7.4$ Izmit earthquake of 1999 August 17", Geophys. J. Int., 148, pp. 139-152 (2002).

51. Monterroso Juarez, D.A. "Statistical seismology studies in central America, $b$ value, seismic hazard and seismic quiescence", Comprehensive Summaries of Uppsala Dissertations from the Faculty of Science and Technology, 897, pp. 1-27 (2003).

52. Bhatt, K.M. and Kumar, S. "Anomalous b-value in seismogenic layer of Bhuj Region", J. Ind. Geophysical Union, 13(3), pp. 99-106 (2009).

53. Zafarani, H., Rahimi, M., Noorzad, A., Hassani, B. and Khazaei, B. "Stochastic simulation of strongmotion records from the 2012 Ahar-Varzaghan dual earthquakes, northwest of Iran", Bull. Seismolo. Soc. Am., 105(3), pp. 1419-1434 (2015).

\section{Biographies}

Salma Ommi received the BSc in Physics from AlZahra University, Tehran, Iran, in 1997-2001. She graduated from Moscow State University named after 
M.V. Lomonosov in June 2005. She is PhD Student at the International Institute of Earthquake Engineering and Seismology. Her research interests span a wide range of topics including Earthquake Prediction and Hazard Analysis.

Hamid Zafarani graduated as a civil engineer from University of Tehran in 1998. He finished MSc at University of Tehran in 2000, and obtained his PhD degree from University of Tehran in 2007. Currently, he is an Associate Professor at International Institute of Earthquake Engineering and Seismology (IIEES). His research interests span a wide range of topics including Earthquake Simulation, Hazard Analysis, Numerical Methods, Earthquake Prediction, and Strong Motion Studies. The results of his research have been published in over 100 papers in international journals, conference proceedings, book chapters, and research reports. 